\title{
Allocleaning behavior by the sentinel crab Macrophthalmus banzai: a case of mutual cooperation
}

\author{
Yurika Fujishima $\cdot$ Keiji Wada
}

Received: 12 November 2012/Accepted: 3 January 2013/Published online: 17 January 2013

(C) Japan Ethological Society and Springer Japan 2013

\begin{abstract}
The macrophthalmid crab Macrophthalmus banzai performs allocleaning behavior, in which an individual feeds off the carapace or walking legs of a conspecific male or female. Cleaning continues until the recipient ('cleanee') rejects the cleaning or the cleaner ceases cleaning. In cases where the recipient did not reject the cleaning, the cleanee often retreated to its own burrow site after the cleaner ceased cleaning, allowing the cleaner to feed on its territory. We suggest that this is mutual cooperation, in which the cleaner assists the recipient to clean the body surface, and the recipient in return provides a feeding ground for the cleaner. Using field observation, we explored the factors responsible for the retreat of the cleanee in response to the cleaning behavior. Factors influencing the retreat of the cleanee were the time of the cleaning incident relative to low tide, the cleanee's position relative to its own burrow, and the duration of the cleaning bout. The third factor showed that retreat was more common when the cleaning was thorough, which suggests that allocleaning is a form of mutual cooperation in M. banzai.
\end{abstract}

Keywords Allocleaning · Mutual cooperation · Intertidal crab $\cdot$ Macrophthalmus

\footnotetext{
Y. Fujishima $\cdot$ K. Wada $(\bowtie)$

Department of Biological Science, Faculty of Science,

Nara Women's University, Nara 630-8506, Japan

e-mail: mbanzai@cc.nara-wu.ac.jp

Present Address:

Y. Fujishima

Laboratory of Marine Environmental Microbiology,

Division of Applied Biosciences,

Graduate School of Agriculture,

Kyoto University, Kyoto 606-8502, Japan
}

\section{Introduction}

Genetically unrelated individuals can maintain a mutual cooperation so long as one individual helps another and receives reciprocal assistance some time later (Trivers 1971). Reciprocity has been suggested in a few nonhuman vertebrate species (Wilkinson 1984; Milinski 1987; Godard 1993; de Waal 2000; Krams et al. 2008; Newton-Fisher and Lee 2011). It has also been suggested in some species of the sentinel crab (the genus Macrophthalmus); they perform allocleaning behavior, in which one crab feeds off the carapace or walking legs of another crab (Kitaura and Wada 2004). This is likely to be a mutually beneficial interaction since the cleaner is provided with a food source and the cleanee (the receiver of the cleaning) benefits from having its carapace and appendages cleaned. Many decapod crustaceans are known to self-groom in order to prevent deleterious epibiont- and sediment-fouling of their exoskeleton (Snow 1973; Walker 1974; Bauer 1975, 1977, 1978, 1981; Felgenhaur and Schram 1978). It is likely that cleaning by other animals is able to reach areas that the cleanee cannot reach itself, and is very likely to be beneficial to the cleanee in terms of epibiont and sediment removal. In the sentinel crab $M$. banzai, which is territorial against other individual burrows (Kitaura and Wada 2004), the cleanee sometimes retreats to its burrow after being cleaned (Ueda and Wada 1996). This probably benefits the cleaner because it is able to forage on the sediment surface around the burrow, an area that would be unavailable to it where the occupant of the burrow to remain surface active. It is possible that the cleaning behavior and the retreating behavior is mutual cooperative interaction in which the quality of the cleaning determines the size of the reward (more careful cleaning increases the likelihood of retreating behavior by the cleanee). This paper explores this 
possibility by examining whether the retreating behavior of the cleaned animal is affected by the quality of the cleaning it receives.

\section{Allocleaning behavior}

Macrophthalmus banzai exhibits two types of allocleaning behavior, i.e. long-duration cleaning that is associated with foraging activity (Fig. 1) and short-duration cleaning that is associated with male courtship (Ueda and Wada 1996). Here, we examine long-duration cleaning only. The cleaner and the cleanee can be of either sex and the cleaner is usually smaller than the cleanee (Ueda and Wada 1996). Cleaning is initiated by the cleaner approaching to the cleanee. Cleaning finishes when the cleaner voluntarily ceases cleaning, or when the cleanee rejects the cleaning. Immediately after the cleaning event, the cleanee sometimes retreats to its own burrow, leaving its feeding ground available for use by the cleaner. This is most common (75\%) when the cleanee does not reject the cleaning behavior (Ueda and Wada 1996).

\section{Materials and methods}

\section{Field observation}

A field study was conducted on a tidal flat in Uchinoura, Tanabe, Wakayama, Japan $\left(33^{\circ} 70^{\prime} \mathrm{N}, 135^{\circ} 38^{\prime} \mathrm{E}\right)$. Data were collected for 3-4 h within the exposure period (5-6 h) over 3-5 days surrounding spring tide (a total of 29 days) in April-August and October in 2010. During the study

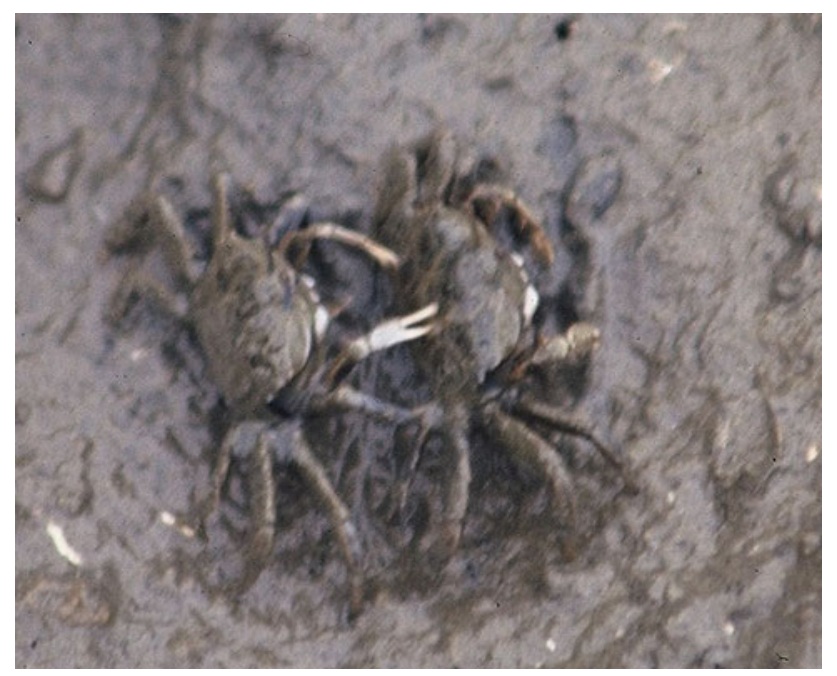

Fig. 1 Allocleaning behavior (long-duration cleaning) in Macrophthalmus banzai period, the air temperature at low tide ranged from 18.0 to $33.3{ }^{\circ} \mathrm{C}$, with the average being $27.4{ }^{\circ} \mathrm{C}$.

An observation area $\left(25 \mathrm{~m}^{2}\right)$ was established where M. banzai was abundant (intertidal height: $5-20 \mathrm{~cm}$ below mean tide level). Groups of crabs, each consisting of 2-8 individuals, were observed and filmed with a video camera (Everio Hi-Vision HardDisk Movie GZ-HD320; Victor) fastened on the bottom for 15-30 min. When allocleaning was observed ( $n=63$ occasions), we waited until the interaction was complete before measuring the distance between the burrows of the cleaner and the cleanee and capturing both crabs. We measured their carapace widths and noted their sex.

Among the allocleaning events recorded, 25 where the cleanee did not reject the cleaning behavior, were analyzed to document the following behaviors related to allocleaning: (1) the time of the event relative to dead low tide; (2) the site of the interaction relative to the burrows of both crabs; (3) the duration of the cleaning bout; and (4) occurrence of retreat behavior (retreat: $n=14$ occasions; non-retreat: $n=11$ occasions).

\section{Data analysis}

In order to detect factors influencing retreat of a cleanee after allocleaning event, a generalized linear model was used to identify the factors that affect retreat or non-retreat of the cleanee after cleaning. Retreat or non-retreat of a cleanee was the dependent variable. Explanatory variables were the time of the cleaning occurrence relative to dead low tide, the sexes of the cleaner and the cleanee, the difference in body size between the cleaner and the cleanee, and the duration of the cleaning bout. We used stepwise backward elimination until the $p$ values of all explanatory variables fell below 0.05. All analyses were conducted using JMP v.9.0 (SAS 2010).

\section{Results}

The retreat of a cleanee to its burrow following a cleaning event was affected by the time of the incident relative to dead low tide (likelihood ratio $\chi^{2}=4.29, p=0.038$ ), by the cleanee's position relative to its own burrow (likelihood ratio $\chi^{2}=4.80, p=0.029$ ), and by the duration of cleaning bout (likelihood ratio $\chi^{2}=4.46, p=0.035$ ), but not by the sexes of the cleaner and the cleanee (likelihood ratio $\chi^{2}=6.34$, $p=0.10$ ) or by the difference in body size between the cleaner and the cleanee (likelihood ratio $\chi^{2}=2.89$, $p=0.09$ ). The cleanee is more likely to retreat to its burrow later in the low tide period (time relative to dead low tide, retreat: $\quad$ mean $\pm \mathrm{SD}=47.6 \pm 69.3 \mathrm{~min}$; non-retreat: $5.9 \pm 66.2 \mathrm{~min})$, when the cleanee was located near to its 
own burrow (distance from cleanee to its burrow, retreat: $6.8 \pm 4.5 \mathrm{~cm}$; non-retreat: $7.3 \pm 6.3 \mathrm{~cm}$ ), and when the duration of the cleaning bout was longer (duration, retreat: $32.0 \pm 24.1 \mathrm{~s}$; non-retreat: $22.6 \pm 22.2 \mathrm{~s}$ ).

\section{Discussion}

Cleanees were more likely to retreat later in the low tide period. This might be due to reduced demand for foraging later in the exposure period. If the crabs had completed their feeding and their demand for food was therefore lower, they are more likely to allow their cleaner to use their feeding ground. However, the allied species M. japonicus is known to increase their feeding activity in later exposure periods (Henmi 1984), which contradicts this explanation.

Cleanees that are located near to their own burrows were more likely to retreat after the allocleaning event. This may be simply due to smaller cost for retreating to the burrow when located nearer to the burrow. It is also probable that crabs near to their own burrows have less demand for food than those far from their burrows.

Cleanees were also more likely to retreat when the duration of the cleaning bout was longer. This results in the pattern where crabs that receive better cleaning (more material removed from their bodies) are more likely to allow their cleaner to feed in their activity spaces, while the cleaner receives benefits of feeding in the cleanee's activity space in return to paying the cost of allocleaning. This is suggestive of reciprocity and could operate when the benefit of prolonged cleaning exceeds the cost of allowing the cleaner to forage in his/her activity space.

What is the benefit of the cleanee from allocleaning event? It is likely to remove unwanted materials on the body surface. In the sphaeromatid isopod, for example, the algal growth on the carapace surface is reduced by cleansing activity on other individuals (Glynn 1970). Harboring of epibionts or mud on the body surface can create problems for crustaceans and most of them develop the behavior of self-grooming (Bauer 1975, 1977, 1981). Cleaning of the body surface by other individuals would be beneficial in that it prevents the attachment of epibiont or sediments. Another possible fitness benefit from allocleaning is that the presence of neighbors assists the cleanee in defense against conspecifics (Backwell and Jennions 2004) or against predators (Pratt et al. 2005; Wong et al. 2005). All these benefits should be evaluated for M. banzai in a future study.

Acknowledgments We are thankful to Prof. Y. Yusa and other members of Population and Community Ecology in Nara Women's University for their grateful advice during the course of the study. Our thanks go to Dr. P. Backwell of Australian National University and two anonymous reviewers for reading drafts of the manuscript. Thanks are also due to staff of the Seto Marine Biological Laboratory of Kyoto University for their support and hospitality during our field research.

\section{References}

Backwell RYP, Jennions DM (2004) Coalition among male fiddler crabs. Nature 430:417

Bauer TR (1975) Grooming behavior and morphology of the caridean shrimp Pandalus danae Stimpson (Decapoda: Natantia: Pandalidae). J Linn Soc 56:45-71

Bauer TR (1977) Antifouling adaptation of marine shrimp (Crustacea: Decapoda: Caridea): functional morphology and adaptive significance of antennular preening by the third maxillipeds. Mar Biol 40:261-276

Bauer TR (1978) Antifouling adaptations of caridean shrimps: cleaning of the antennal flagellum and general body grooming. Mar Biol 49:69-82

Bauer TR (1981) Grooming behavior and morphology in the decapod Crustacea. J Crust Biol 1:153-173

de Waal EBM (2000) Payment for labour in monkeys. Nature 404:563

Felgenhaur BE, Schram RF (1978) Differential epibiont fouling in relation to grooming behavior in Palaemonetes kadiakensis. Fieldiana (Zoology) 72:83-100

Glynn WP (1970) Growth of algal epiphytes on a tropical marine isopod. J Exp Mar Biol Ecol 5:88-93

Godard R (1993) Tit for tat among neighboring hooded warblers. Behav Ecol Sociobiol 33:45-50

Henmi Y (1984) The description of wandering behavior and its occurrence varying in different tidal areas in Macrophthalmus japonicus (De Haan) (Crustacea: Ocypodidae). J Exp Mar Biol Ecol 84:211-224

Kitaura J, Wada K (2004) Allocleaning, fighting, waving and mating behavior in sentinel crabs (Brachyura: Ocypodidae: Macrophthalmus). Crust Res 33:72-91

Krams I, Krama T, Igaune K, Mand R (2008) Experimental evidence of reciprocal altruism in the pied flycatcher. Behav Ecol Sociobiol 62:599-605

Milinski M (1987) Tit for tat in sticklebacks and the evolution of cooperation. Nature 325:433-435

Newton-Fisher NE, Lee PC (2011) Grooming reciprocity in wild male chimpanzees. Anim Behav 81:439-446

Pratt EA, McLain KD, Berry SA (2005) Variation in the boldness of courting sand fiddler crabs (Uca pugilator). Ethology 111:63-76

SAS Institute Inc (2010) JMP IN, version 9.0.0, Japanese edn, Cary

Snow PJ (1973) The antennular activities of the hermit crab, Pagurus alaskensis (Benedict). J Exp Mar Biol Ecol 58:745-765

Trivers RL (1971) The evolution of reciprocal altruism. Q Rev Biol 46:35-57

Ueda K, Wada K (1996) Allocleaning in an intertidal ocypodid crab, Macrophthalmus banzai. J Ethol 14:45-52

Walker G (1974) The occurrence, distribution and attachment of the pedunculate barnacle Octolasmis mülleri (Coker) on the gills of crabs, particularly the blue crab, Callinectes sapidus Rathbun. Biol Bull 147:678-689

Wilkinson GS (1984) Reciprocal food sharing in the vampire bat. Nature 308:181-184

Wong MBB, Bibeau C, Bishop AK, Rosenthal GG (2005) Response to perceived predation threat in fiddler crabs: trust thy neighbor as thyself? Behav Ecol Sociobiol 58:345-350 